\title{
Analysis of D-Chiro inositol in lowering androgen levels in PCOS patients
}

Anza Ashraf ( $\square$ anzaashraf28@gmail.com )

Muhammad Bilal Kundi

Syed Usama Arif

MUhammad Asif

Muhammad llyas

Hafsa Rehan

\section{Method Article}

Keywords:

Posted Date: February 9th, 2022

DOI: https://doi.org/10.21203/rs.3.rs-1329990/v1

License: (c) (i) This work is licensed under a Creative Commons Attribution 4.0 International License.

Read Full License 


\section{Abstract}

Background and objectives: Polycystic ovarian syndrome (PCOS) involves dysfunction in the endocrinal, metabolic and reproductive profile among females. D-chiro inositol is a novel treatment agent for improving the endocrinal profile seen in it. The current study aims to evaluate the effect of D-Chiro Inositol in lowering down the androgens levels in patients with PCOS.

Methodology of the study: This randomized trial was carried out at the outpatient of Department of medical sciences during June 2020 to March 2021. 50 females with polycystic ovarian disease were divided randomly into two groups, each of 25 females. One group was give D-Chiro Inositol $(600 \mathrm{mg} / \mathrm{day})$ and the other was given placebo. Androgens levels i.e. LH, FSH and testosterone were assessed at baseline and then after 8 weeks. Treatment effects were compared after 8 weeks by independent sample $T$ test and a $P$ value of $\leq 0.05$ was considered significant.

Results: The mean age of the patients in the treatment (D-Chiro Inositol) group was $28 \pm 8$ year's vs $30 \pm 9$ years in placebo group. The mean BMI of females in D-Chiro Inositol group was $25.7 \pm 3.6 \mathrm{~kg} / \mathrm{m}^{2}$ compared to $25.8 \pm 4.2 \mathrm{~kg} / \mathrm{m}^{2}$ in the placebo group. The mean levels of $\mathrm{LH}, \mathrm{FSH}$ and testosterone were $14.74 \mathrm{mlU} / \mathrm{ml}, 10.19 \mathrm{mlU} / \mathrm{ml}$ and $78.48 \mathrm{ng} / \mathrm{dL}$ in D-Chiro Inositol group vs $17.22 \mathrm{mlU} / \mathrm{ml}, 13.03 \mathrm{mlU} / \mathrm{ml}$ and $86.08 \mathrm{~g} / \mathrm{dl}$ in placebo group. Significant difference was present between both treatment groups $(P$ value $\leq 0.05$ ).

Conclusion: D-Chiro Inositol is a promising drug for the lowering down the androgens levels in polycystic ovarian syndrome.

\section{Introduction:}

Polycystic ovarian syndrome (PCOS) is a composite disorder that involves dysfunction of ovaries ${ }^{1}$. It is defined by the presence of two or more features such as hyperandrogenism, ovulatory dysfunction or polycystic ovaries on ultrasound. It is found is $5-20 \%$ of the females during their reproductive age ${ }^{10}$. Recently, treatment of PCOS with inositols have proven beneficial in the endocrinal and metabolic dysfunction linked with it ${ }^{2,6}$.

Numerous authors have analyzed the impact of D-Chiro Inositol on various variables in females with PCOS. D-Chiro Inositol improves endocrinal parameters such as luteinizing hormone (LH), follicular stimulating hormone (FSH) and testosterone $2,8,11$.D-Chiro Inositol effect is found to be associated with body weight of the females ${ }^{3}$. In those females who are lean and have a body mass index of 20.02-24.4 $\mathrm{kg} / \mathrm{m}^{2}$, D-Chiro Inositol decreases the levels of insulin and free testosterone. It is also found to increase the rate of ovulation. In comparison to this, in females who are obese with polycystic ovarian syndrome, D-Chiro Inositol helps in improving endocrine parameters such as serum testosterone, serum androstenedione and gonadotropin releasing hormone induced LH response. It also causes a decrease in body mass index as well as improves sensitivity of insulin markers ${ }^{2,14}$. 
A lot of international research is present on treatment of PCOS with D-Chiro Inositol. However, data in Pakistan is lacking regarding the efficacy of this evolving drug. So the aim of current research is to evaluate the effect of D-Chiro Inositol in lowering down androgens levels in female patients with PCOS. This will help in raising awareness among treating physicians regarding this new therapy that can help in reducing morbidity associated with this condition.

\section{Methodology:}

This randomized trial was carried out at the outpatient of Department of medical Sciences during June 2020 to March 2021. Total 50 females, between 18-45 years of age, who fulfilled the definition of polycystic ovarian syndrome i.e. having 2 out of these 3 features such as hyperandrogenism (evident clinically by hirsutism), anovulation and presence of polycystic ovaries on ultrasound, were registered in the research after obtaining informed consent and seeking hospital ethical committee approval. Patients

who were already taking medications previously for polycystic ovarian syndrome were excluded as well as patients with hypothyroidism and with raised prolactin levels.

After noting down the demographic details of the patients, baseline levels of $\mathrm{LH}, \mathrm{FSH}$ and testosterone were measured and recorded. The participants that were eligible were designated randomly to 1 of the 2 groups of treatment in equal proportion ( 25 females in each group) for 8 weeks: one group was given DChiro Inositol alone ( $600 \mathrm{mg} /$ day) and the other was given placebo alone. The randomization of participants was done through a table generated by a computer so that in each group the numbers of participants could be approximately equalized. Assignment of patients into groups was done after completion of all screening assessments. To make concealment of the assigned treatment certain, a research pharmacist carried out randomization without the investigator, who did it at another center and provided the medications in containers that were coded and had similarly looking capsules of D-Chiro Inositol or placebo handed over by the manufacturer. Placebo was a B-complex vitamin, which was considered to have no effect on androgen levels. After completion of 8 weeks, serum levels of LH, FSH and testosterone were again assessed and compared with the levels at baseline and were subjected to analysis statistically.

Data was analyzed using SPSS version 17.0. Quantitative data such as age, body mass index, LH, FSH and testosterone was assessed as mean and standard deviation. Qualitative data such as obesity, presence of diabetes was assessed as frequency and percentages. Data was stratified for age, obesity and presence of diabetes. Post stratification Chi square test was applied to deal with the effect modifiers and a $P$ value of $\leq 0.05$ was considered significant. Independent sample T-test was applied to compare the effects of both treatment. A p value of $\leq 0.05$ was considered significant.

\section{Results:}

A total of 50 female patients with Polycystic Ovarian Disease were assessed. The mean age of the patients in the treatment (D-Chiro Inositol) group was 28 years with a standard deviation of 8 and mean 
age in the placebo group was 30 years with standard deviation of 9 . The mean body mass index of females in D-Chiro Inositol group was $25.7 \pm 3.6 \mathrm{~kg} / \mathrm{m}^{2}$ compared to $25.8 \pm 4.2 \mathrm{~kg} / \mathrm{m}^{2}$ in the placebo group. The mean LH, FSH and testosterone levels were $18.6 \mathrm{mlU} / \mathrm{ml}, 13.59 \mathrm{mlU} / \mathrm{ml}$ and $90.7 \mathrm{ng} / \mathrm{dl}$ at baseline in the treatment group respectively. The mean $\mathrm{LH}, \mathrm{FSH}$ and testosterone levels were $17.72 \mathrm{mlU} / \mathrm{ml}$, $13.6 \mathrm{mlU} / \mathrm{ml}$, and $89.04 \mathrm{ng} / \mathrm{dl}$ at baseline in the placebo group respectively. Among 25 female patients who were treated With D-Chiro Inositol, 11 (44\%) had obesity and $5(20 \%)$ had diabetes, whereas among 25 female patients who received placebo, $10(40 \%)$ had obesity and $4(16 \%)$ had diabetes. The mean levels of LH, FSH and testosterone were $14.74 \mathrm{mIU} / \mathrm{ml}, 10.19 \mathrm{mlU} / \mathrm{ml}$ and $78.48 \mathrm{ng} / \mathrm{dL}$ in D-Chiro Inositol group vs $17.22 \mathrm{mlU} / \mathrm{ml}, 13.03 \mathrm{mlU} / \mathrm{ml}$ and $86.08 \mathrm{~g} / \mathrm{dl}$ in placebo group after 8 weeks.

Independent sample T-test was applied to look for the difference between the two groups. The results revealed that the group which received D-Chiro Inositol showed significant reduction in the levels of androgens i.e. LH, FSH and Testosterone as indicated by a P-value of $\leq 0.05$ and the independent sample $T$ test revealed that treatment with D-Chiro Inositol was significantly better compared to placebo in lowering down the levels of androgens ( $P$ value $\leq 0.05)$.

Stratification of data was done for age, obesity and presence of diabetes. Chi square test was applied after stratification to see the impact of these modifiers and it was found that none of these factors had any significant impact on the treatment outcome.

Table 1

FEATURES OF 50 FEMALES WITH PCOS AT BASELINE AND AFTER THE ADMINISTRATION OF D-CHIRO INOSITOL OR PLACEBO FOR EIGHT WEEKS

\begin{tabular}{|c|c|c|c|c|}
\hline \multirow[t]{2}{*}{ CHARACTERISTICS } & \multicolumn{2}{|c|}{ D-CHIRO INOSITOL GROUP (N=25) } & \multicolumn{2}{|c|}{$\begin{array}{l}\text { PLACEBO GROUP } \\
(\mathrm{N}=25)\end{array}$} \\
\hline & $\begin{array}{l}\text { BASELINE } \\
\text { (Before D-Chiro } \\
\text { Inositol ) }\end{array}$ & $\begin{array}{l}\text { AFTER D-CHIRO INOSITOL } \\
\text { TREATMENT }\end{array}$ & $\begin{array}{l}\text { BASELINE } \\
\text { (Before } \\
\text { Placebo) }\end{array}$ & $\begin{array}{l}\text { AFTER } \\
\text { PLACEBO }\end{array}$ \\
\hline Age (years) & $28 \pm 8$ & - & $30 \pm 9$ & - \\
\hline BMI $\left(\mathrm{kg} / \mathrm{m}^{2}\right)$ & $25.7 \pm 3.6$ & - & $25.8 \pm 4.2$ & - \\
\hline Obesity & $11(44 \%)$ & - & $10(40 \%)$ & -- \\
\hline Diabetes & $5(20 \%)$ & - & $4(16 \%)$ & -- \\
\hline $\mathrm{LH}(\mathrm{mlU} / \mathrm{ml})$ & $18.6 \pm 3.78$ & $14.74 \pm 4.52 *$ & $17.72 \pm 3.31$ & $17.22 \pm 3.99$ \\
\hline FSH (mlU/ml) & $13.59 \pm 3.2$ & $10.19 \pm 3.03^{\star \star}$ & $13.6 \pm 2.96$ & $13.03 \pm 3.02$ \\
\hline $\begin{array}{l}\text { Testosterone } \\
(\mathrm{ng} / \mathrm{dl})\end{array}$ & $90.7 \pm 14.79$ & $78.48 \pm 25.4^{\star \star \star}$ & $89.04 \pm 14.75$ & $86.08 \pm 18.23$ \\
\hline
\end{tabular}

* $\mathrm{P}=0.04$ after comparing with the placebo group 
** $\mathrm{P}=0.002$ after comparing with the placebo group

$\star \star \star P=0.03$ after comparing with the placebo group

\section{Discussion:}

D-Chiro Inositol $(\mathrm{DCl})$ is an effective treatment which leads to improvement in the functions of ovaries along with improved metabolism in females with polycystic ovarian syndrome. The current research evaluated the effect of D-Chiro Inositol in lowering down the levels of androgens specifically luteinizing hormone (LH), follicular stimulating hormone (FSH) and testosterone in females with polycystic ovaria syndrome. It was found that treatment with D-Chiro Inositol led to significant reduction in the levels of $\mathrm{LH}$, FSH and testosterone and was statistically significant compared to the placebo group.

In 2015, Antonio Simone Lagana conducted a study and evaluated the effect of DCl on functions of ovaries and metabolism in females having polycystic ovarian syndrome ${ }^{2}$. The patients were given $\mathrm{DCl}$ in a dose of 1 gram per day along with folic acid 400 mcg per day orally for a period of 6 months. The authors assessed the effect of treatment on body mass index, blood pressure (both systolic and diastolic), serum LH, FSH, free and total testosterone, androstenedione and prolactin levels and also assessed the impact of treatment on menstrual regularity. The results revealed that D-Chiro Inositol resulted in significantly lower systolic blood pressure, LH levels, FSH, free and total testosterone levels, decrease androstenedione and prolactin amount ${ }^{2}$. They also found that regularization of menstrual cycle after treatment was significant statistically too. The current research result also yielded similar effect of treatment with D-Chiro Inositol on LH, FSH and testosterone. However, the current study did not evaluate the effect on other endocrinal parameters or did not see the effect on blood pressure or regularity of menstrual cycle. So further studies in this context should be carried out.

\section{Conclusion:}

In conclusion, treatment of polycystic ovarian syndrome with D-Chiro Inositol is effective. It is a promising therapy in patients with PCOS and results in an improved hormonal profile. Despite the current study data, there is still a further need of evaluating larger samples and carrying out studies with more statistical power so that the outcomes after treating with d-chiro inositol can be clarified.

\section{Declarations}

Competing interests: The authors declare no competing interests.

\section{References}

1. Unfer V, Nestler JE, Kamenov ZA, Prapas N, Facchinetti F. Effects of inositol (s) in women with PCOS: a systematic review of randomized controlled trials. International journal of endocrinology. 
2016;2016.

2. Lagana AS, Barbaro L, Pizzo A. Evaluation of ovarian function and metabolic factors in women affected by polycystic ovary syndrome after treatment with D-Chiro-Inositol. Archives of Gynecology and Obstetrics. 2015 May 1;291(5):1181-6.

3. Benelli E, Del Ghianda S, Di Cosmo C, Tonacchera M. A combined therapy with myo-inositol and Dchiro-inositol improves endocrine parameters and insulin resistance in PCOS young overweight women. International journal of endocrinology. 2016;2016.

4. Laganà AS, Vitale

5. SG, Noventa M, Vitagliano A. Current management of polycystic ovary syndrome: from bench to bedside. International journal of endocrinology. 2018;2018.

6. Mishra M, Rathoria R, Agarwal A. THE THERAPEUTIC ROLE OF MYO-INOSITOL AND DCHIROINOSITOL TO PREVENT MENSTRUAL DYSFUNCTION IN PCOS WOMEN. International Journal of Scientific Research. 2019 Jul 11;8(2).

7. Kalra B, Kalra S, Sharma JB. The inositols and polycystic ovary syndrome. Indian journal of endocrinology and metabolism. 2016 Sep;20(5):720.

8. Shah P. Myo-inositol and D-chiro-inositol as a Therapeutic Consideration for Polycystic Ovarian Syndrome. EC Endocrinology and Metabolic Research. 2019;4:103-6.

9. Pundir J, Psaroudakis D, Savnur P, Bhide P, Sabatini L, Teede H, Coomarasamy A, Thangaratinam S. Inositol treatment of anovulation in women with polycystic ovary syndrome: a meta-analysis of randomised trials. BJOG: An International Journal of Obstetrics \& Gynaecology. 2018 Feb;125(3):299-308.

10. Rocha AL, Oliveira FR, Azevedo RC, Silva VA, Peres TM, Candido AL, Gomes KB, Reis FM. Recent advances in the understanding and management of polycystic ovary syndrome. F1000Research. 2019;8.

11. Azziz R, Carmina E, Chen Z, Dunaif A, Laven JS, Legro RS, Lizneva D, Natterson-Horowtiz B, Teede HJ, Yildiz BO. Polycystic ovary syndrome. Nature reviews Disease primers. 2016 Aug 11;2:16057.

12. Sortino MA, Salomone S, Carruba MO, Drago F. Polycystic ovary syndrome: insights into the therapeutic approach with inositols. Frontiers in pharmacology. 2017 Jun 8;8:341.

13. Mendoza N, Diaz-Ropero MP, Aragon M, Maldonado V, Llaneza P, Lorente J, et al. Comparison of the effect of two combinations of myo-inositol and D-chiro-inositol in women with polycystic ovary syndrome undergoing ICSI: a randomized controlled trial. Gynecological Endocrinology. 2019 Mar 8:1-6.

14. Nestler JE, Unfer V. Reflections on inositol (s) for PCOS therapy: steps toward success.

15. Unfer V, Monastra G. On the therapy for polycystic ovary syndrome. Indian journal of endocrinology and metabolism. 2017 Jul 1;21(4):639. 